\title{
Coupled Simulation between CFD and Multizone Models Based on Modelica Buildings Library to Study Indoor Environment Control
}

\author{
Wei Tian ${ }^{1} \quad$ Wangda Zuo ${ }^{1, *} \quad$ Thomas A. Sevilla $^{1} \quad$ Michael D. Sohn ${ }^{2}$ \\ ${ }^{1}$ Department of Civil, Architectural, and Environmental Engineering, University of Miami, USA, \\ w.tian@umiami.edu w.zuo@miami.edu, t.sevilla@umiami.edu; *Corresponding Author \\ ${ }^{2}$ Sustainable Energy Systems Group, Lawrence Berkeley National Laboratory, USA, mdsohn@lbl .gov
}

\begin{abstract}
Multizone models are widely used in building airflow and energy performance simulations because they are often suitable for the analysis needed, and due to their fast computation speed. However, the results provided by the multizone models are sometimes limited due to the underlying well-mixed assumption of the air in a zone (e.g., a room). For zones where this assumption is not suitable, a Computational Fluid Dynamics (CFD) models may be needed. This paper proposes a coupled simulation model between the multizone and CFD model, which in the paper is fast fluid dynamics, a freely available and publicly released program. The model allows the simulation of a dynamic interaction between airflow and Heating, Ventilation and Air-Conditioning (HVAC) systems for buildings with stratified airflow distribution in some of the zones. The approach is implemented using Modelica and its buildings library. In this presentation, we first discuss the design and implementation of a data synchronization strategy between the two models. We then show a possible validation of the implementation by comparing the simulated results with experimental data from previous research. Finally, we perform a case study by linking a Variable Air Volume (VAV) terminal box to space in order to evaluate the capability of the coupled simulation. Finally, further research needs are discussed at the end of the paper.
\end{abstract}

Keywords: CFD, Multizone, Coupled Simulation

\section{Introduction}

On average, Americans spend $90 \%$ of their time indoors (Kats 2003). Therefore, in order to maintain thermal comfort using HAVC systems, buildings consume about $41 \%$ of total energy in the US (Department of Energy 2011). However, the current indoor environment is far from satisfactory. The estimated loss of productivity due to the poor indoor environment is up to 160 billion dollars in the US (Fisk 2000). Thus, it is critical to improve the indoor environment while decreasing the energy consumption.

To improve the design of HVAC system and indoor environment, we can use numerical simulation. On the airflow simulation, there are various models available, such as multizone models, zonal models, and CFD models (Chen 2009). For the HVAC simulation, there are some conventional building performance simulation programs such as EnergyPlus (Crawley et al. 2001), ESP-r (Strachan et al. 2008), IDA Indoor Climate and Energy (IDA ICE) (Kropf and Zweifel 2001), TRYNSYS (Klein et al. 1976), and some advanced techniques such as Modelica-based modeling (Wetter 2009).

Multizone models are widely used in building energy performance simulation programs to save computation time. By asserting that the air is suitably well mixed in a zone, a multizone model solves the mass balance equation and energy balance equation in a significantly faster fashion, compared to the speed of the CFD models (Chen 2009). However, the underlying well-mixed air assumptions for multizone models may be invalid if, for example, the air in the room is stratified. In this case, the multizone models may calculate incorrect results (Wang and Chen 2008).

To model a multiple air distribution type zone building, Wang (Wang 2007) proposed dynamic coupling between CFD and multizone models. As a result, the multizone models are adopted for zones with well-mixed air distribution and CFD model is used for zones with stratified air distribution. At the synchronization time, data is exchanged between the CFD and multizone models. The data exchange is performed iteratively to ensure a fully-converged solution. To achieve convergence and stability, Wang and Chen (2005) recommended transferring pressure data from multizone models to CFD while simultaneously giving airflow rates from CFD to multizone models. While significant, however, their work only focused on the airflow movement and did not demonstrate their approach for buildings that included HVAC systems, and with HVAC controls.

To model the control and distribution of airflow movement in a building with multiple zones, it is necessary to integrate the HVAC system modeling, multizone model, and CFD model. In previous work, multizone models were implemented in Modelica (Wetter 2006a). Similar models are also implemented in the Modelica Buildings library (Wetter et al. 2014) which can link to the HVAC system model to study the 
control of airflow. Besides the multizone models, there are several CFD model implementations in Modelica such as a sub-zonal CFD model (Bonvini et al. 2014) and VEPZO (Norrefeldt et al. 2012). Moreover, a externally coupled simulation model between CFD model for airflow, HVAC, building envelopes and control was implemented in the Modelica Buildings library to enable the study of their dynamic interactions (Zuo et al. 2016). The coupled simulation model was then validated and used to study a case with stratified non-isothermal airflows with an idealized constant air volume system. The results demonstrated that the model is capable of capturing the dynamics of the system.

Based on the previous efforts, this paper implements the coupled simulation of CFD and multizone models in Modelica to study the interaction between airflow movement and HVAC system. This paper first discusses the data synchronization strategy used in the implementation. Then it focuses on the validation by using a case with well-controlled boundary conditions. Finally, a more complex case stemmed from research (Wang 2007) was used to further evaluate the capability of the coupled simulation.

\section{Methodologies}

A quasi-dynamic data synchronization strategy (Zhai et al. 2002; Tian and Zuo 2013) is used for the coupled simulation. As shown in Figure 1, CFD and multizone models exchange data at a given data synchronization point $t_{n}$ and then run on their own till the next point $t_{n+1}$. The exchange of information $\boldsymbol{x}$ is dependent on different scenarios. Note that CFD models have a constant time step size and multizone models programmed in Modelica uses an adaptive time step size.

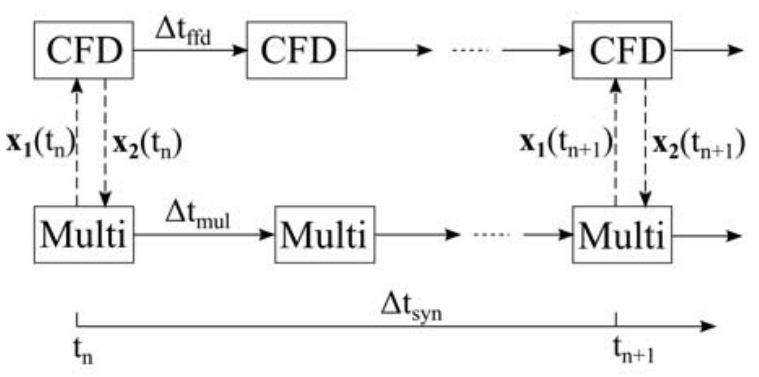

Figure 1. Two-way data synchronization strategy

As shown in Figure 2, we present a simplified physical representation of the data exchange strategy. In this scenario, Zone 1 is simulated by CFD as a nonuniform momentum distribution formed by the inlet directly facing one of the outlets. The mass flow rate and temperature at the inlet of the CFD zone are already known. CFD models feed the mass flow rates and temperature values at two outlets, which are the averages for time and area, to the multizone modeled zones, namely, Zone 2 and Zone 3.

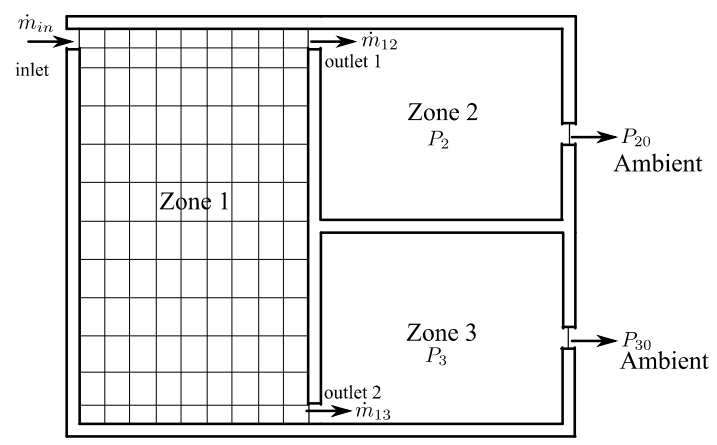

Figure 2. Sketch of the case on which data exchange was implemented

Note that in this simplified data synchronization scheme there is no pressure information exchanged mutually between two programs. After receiving the mass flow rate at openings to from the CFD models, the multizone models can then determine the pressure at zones and mass flow rates at the openings using the equation introduced in the next section.

\section{Mathematical Description of Multizone model and FFD}

FFD solves the Navier-Stokes equations:

$$
\frac{\partial \boldsymbol{U}_{i}}{\partial t}=-\boldsymbol{U}_{j} \frac{\partial \boldsymbol{U}_{i}}{\partial \boldsymbol{x}_{j}}+v \frac{\partial^{2} \boldsymbol{U}_{i}}{\partial \boldsymbol{x}_{j}^{2}}-\frac{1}{\rho} \frac{\partial P}{\partial \boldsymbol{x}_{i}}+\boldsymbol{F}_{i}
$$

where $\boldsymbol{U}_{i}$ and $\boldsymbol{U}_{j}$ are the velocity component in $\boldsymbol{x}_{i}$ and $\boldsymbol{x}_{j}$ directions, respectively, $v$ is the kinematic viscosity, $\rho$ is the fluid density, $P$ is the pressure, $t$ is the time, and $\boldsymbol{F}_{i}$ is the source term, such as the buoyancy force. FFD splits the Navier-Stokes equation into the following three equations:

$$
\begin{gathered}
\frac{\partial \boldsymbol{U}_{i}}{\partial t}=-\boldsymbol{U}_{i} \frac{\partial \boldsymbol{U}_{i}}{\partial \boldsymbol{x}_{j}} \\
\frac{\partial \boldsymbol{U}_{i}}{\partial t}=v \frac{\partial^{2} \boldsymbol{U}_{i}}{\partial \boldsymbol{x}_{j}^{2}}+\boldsymbol{F}_{i} \\
\frac{\partial \boldsymbol{U}_{i}}{\partial t}=-\frac{1}{\rho} \frac{\partial P}{\partial \boldsymbol{x}_{i}}
\end{gathered}
$$

FFD first solves the advection equation (2) using a semiLagrangian method (Courant et al. 1952). It then solves the diffusion equation (3) with an implicit scheme. Finally, it solves the pressure equation (4) together with the continuity equation

$$
\frac{\partial \boldsymbol{U}_{i}}{\partial \boldsymbol{x}_{i}}=0
$$

using a projection-correction method (Chorin 1967). FFD also applies a similar algorithm to solve the conservation equations of energy and species. The detailed implementation of sequential FFD model can 
be found in (Zuo and Chen 2009; Jin et al. 2012). One can also refer to the parallelized FFD model by CUDA and OpenCL in these literature (Zuo and Chen 2010; Yang 2013; Tian, Sevilla, and Zuo 2017).

Typical multizone models, for example, CONTAMW, use the power law to calculate the mass flow rate $\dot{Q}_{i j}$ from zone $i$ to zone $j$ (Dols and Walton 2002). In Modelica Buildings library, the $\dot{Q}_{i j}$ is defined as follows (Wetter 2006b):

$$
\dot{Q}_{i j}=C_{d} A \sqrt{2 / \rho} \Delta P^{m}
$$

where $C_{d}$ is the discharge coefficient normally ranging between 0.6 to 0.75 ; $A$ is the area size of the opening; $\rho$ is the density of the air; $m$ is constant, which is 0.5 for large openings. $\Delta P$ is the pressure difference consisting of total pressure difference $\left|P_{i}-P_{j}\right|$, pressure difference due to wind $\Delta P_{w}$, and pressure difference due to density and elevation difference $\Delta P_{t}$ (Wang and Chen 2007).

Since Modelica is an equation-based, object-oriented modeling language (Fritzson 1998), the sign of $\dot{Q}_{i j}$ can be automatically determined based on the pressure in two zones. Thus, we can write the mass conservation for zone $i$ as:

$$
\frac{d m_{i}}{d t}=\sum_{j=1}^{n} \dot{Q}_{i j}+F_{i}
$$

where $m_{i}$ is the mass at zone $i ; n$ is number of surrounding neighbours to zone $j ; F_{i}$ is the air mass source in the zone $i$. Since the flow in buildings is typically incompressible, we can assume that $m_{i}$ is not changing with the time. Once the boundary conditions are applied, the pressure at each zone and mass flow rate between neighboring zones can be uniquely determined.

\section{Model Implementation}

The key obstacle to the implementation is to realize the extraction of the flow rates and the value of the scalar variables at the outlets from CFD and to feed them to the multizone model. To overcome the problem, we put virtual sensors at the outlets to obtain the necessary information. For detailed information of the CFD model in the Modelica Buildings library, please refer to previous research (Zuo et al. 2014).

Figure 3 shows the detailed implementation. The CFD zone is modeled using the CFD model in the Modelica Buildings library. Three real inputs for radiative heat gain, convective heat gain, and latent heat gain, are connected to the CFD model. At the lower part of the figure, there are fluid and heat ports connected to the CFD model as boundary conditions. Note that the CFD model will calculate the mass flow rates at all ports using the mass balance law and the CFD program will assign the tag of inlet or outlet to the ports based on the sign of the mass flow rate. On the right side of the figure, the mass flow rates and temperature at the outlets from CFD were given to the prescribed fluid mover through the first order delay model. The delay model is used to mimic reality by making the mass flow rate increase gradually.

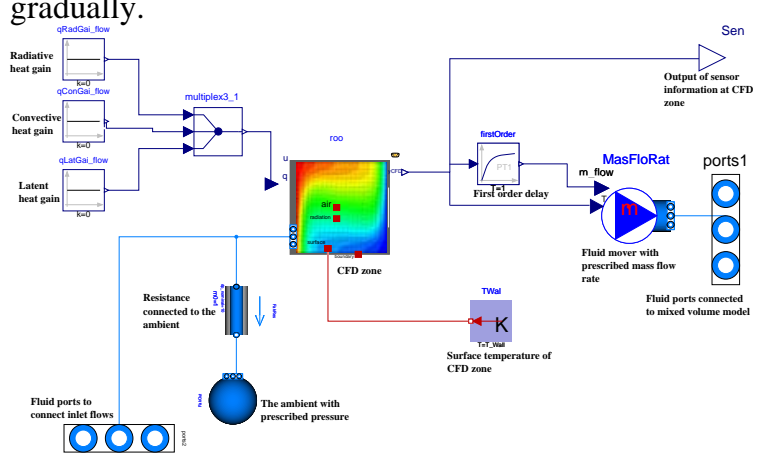

Figure 3. Diagram of Modelica model for coupling

In this paper, we chose Fast Fluid Dynamics (FFD), as an intermediate model between multizone and CFD models, due to its fast computation speed. By sacrificing some accuracy the FFD method is shown to be about 50 times faster than CFD programs if running on the CPU (Zuo and Chen 2009). By taking advantage of the GPU, the FFD program can gain another 30 times computation acceleration, which will be added up to achieve 1500 times faster than CFD program running on CPU (Zuo and Chen 2010).

\section{Case Study}

\subsection{Isothermal with non-uniform momentum distribution}

We used one of the three experiments conducted by Wang and Chen (2009) to validate the coupled simulation model. As shown in Figure 4, space consists of four zones. Zone 1, which has one inlet and two outlets, is simulated by FFD, due to the non-uniform momentum distribution as the inlet is directly facing opening 1. Other zones were simulated using multizone models.

Figure 5 shows the Modelica representation of the validation case. A prescribed fluid mover was connected to the CFD zone (Zone 1) to provide the inlet boundary conditions for the FFD program. Other zones were simulated by the multizone models, namely, MixingVolume. The openings were simulated by Orifice, which nonlinearly correlates the mass flow rates with a pressure difference between zones. 


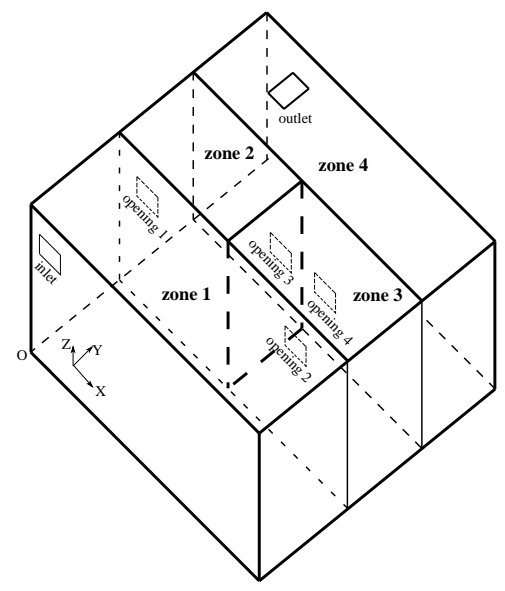

Figure 4. Schematic of a building with two rooms

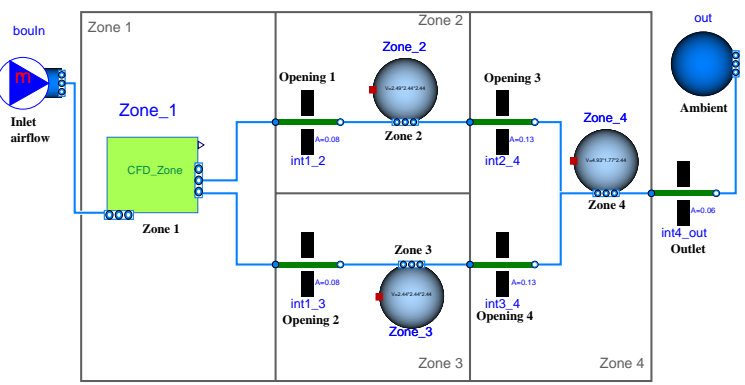

Figure 5. Diagram of Modelica model for a building with two rooms

The radiative heat gain, the convective heat gain, and the latent heat gain inside CFD_Zone model are all set to zero. The inlet mass flow rate is changing at 0.033 , $0.053,0.105,0.14$, and $0.215 \mathrm{~m}^{3} / \mathrm{s}$. Since this experiment is essentially isothermal, we set the inlet temperature, the temperature at all walls of Zone 1 and initial temperature at fluid cells as $10{ }^{\circ} \mathrm{C}$. The data synchronization time step is set up to $5 \mathrm{~s}$. The simulation span is $100 \mathrm{~s}$ and the Radau solver is used. The residual is regulated to be below $1 \mathrm{E}-6$.

FFD uses a mesh of $34 \times 12 \times 18$. The time step size for the former two mass flow rates is $0.1 \mathrm{~s}$ and for others is $0.05 \mathrm{~s}$. To simulate the turbulence introduced by the high-velocity jet, we employed the zero equation model proposed by Chen and Xu (1998).

Figure 6 shows the mass flow rates ratio at opening 1 and opening 2 in Zone 1. Our simulated results have good agreement with the experiment when the inlet mass flow rate is generally larger. Due to the fact that there is considerable numerical viscosity (can be acted as turbulence viscosity) in the FFD model as a result of the solution method, we tuned the coefficients of the zero equation turbulence model.

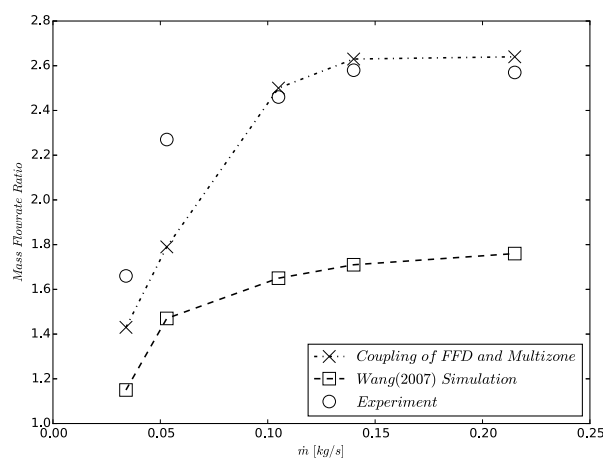

Figure 6. Validation results of mass flow rate ration at opening 1 and opening 2

\subsection{Multizone airflow with a VAV terminal box}

In a validation effort, we demonstrate that the coupled simulation model can study the airflow distribution for space with a non-uniform momentum distribution. After adding a VAV terminal box to the validation case, the case study aimed to investigate the control of room temperature for Zone 1, as shown in Figure 7. To increase the efficiency of temperature control, we increased the length of the inlet (in the $\mathrm{X}$ direction) by $0.53 \mathrm{~m}$, in order to insert more air from the terminal box in the room.

Here we modeled the heat transfer and radiative heat transfer through and between the envelopes in Zone 1 in Modelica. The exterior surface temperature for floor and other walls are $25^{\circ} \mathrm{C}$ and $27^{\circ} \mathrm{C}$, respectively. The initial temperature of the space is $30^{\circ} \mathrm{C}$. The objective is to sustain $25^{\circ} \mathrm{C}$ temperature for occupant zone of Zone 1 , which is in the lower half part, by adjusting the VAV terminal box.

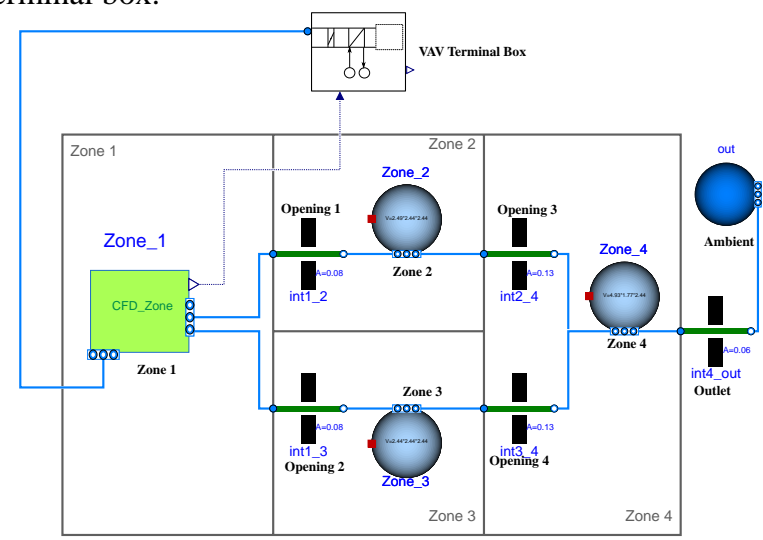

Figure 7. VAV terminal box with validation space

Figure 8 illustrates the detailed model of VAV terminal box. Since we isolated the room from a VAV system which serves multiple rooms, we assume that the pressure difference at terminal box and space outlet as 
constant. Thus, we set the pressure of the cold air source as $20 \mathrm{~Pa}$. The temperature of the cold air source is constant as $16{ }^{\circ} \mathrm{C}$. The opening of the valve in the cold air loop is adjustable and reheat coil can be turned on by opening the valve in the hot water loop. A controller is implemented to coordinate the opening position of the valve in cold air and hot water loop.

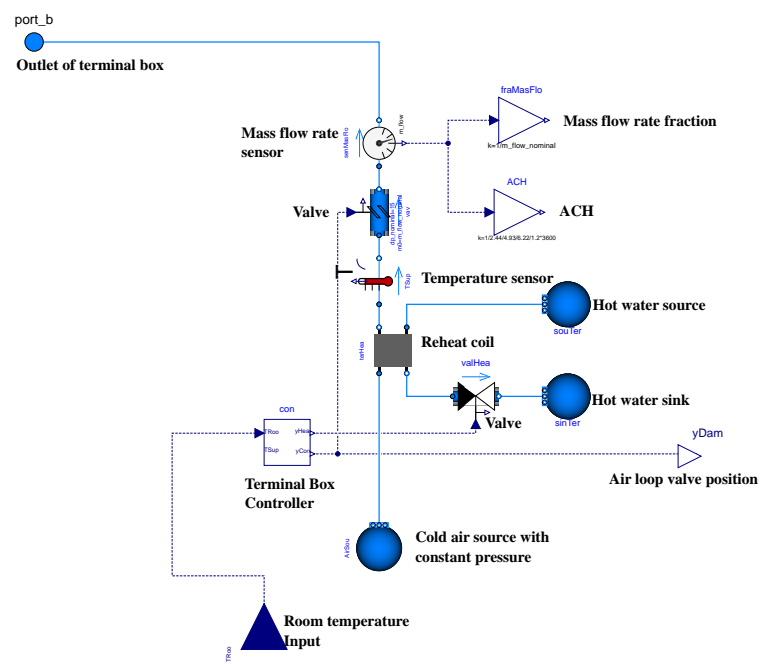

Figure 8. VAV terminal box

As shown in Figure 9, we implemented a pressuredependent control logic (Liu et al. 2012). The occupant zone temperature signal is first sent to adjust the valve position in the cooling air loop, which is at the lower part of the figure. If the valve opening decreases to $30 \%$, which is deemed as the lower limit, then, the reheat coil will be turned on by feeding the opening position signal to the valve of the reheat coil. The control of the reheat coil is shown in the upper part of the figure. To avoid the short cycling of the reheat coil, we added to the controller a hysteresis, which has lower bound of 0.3 and higher bound of 0.4 .

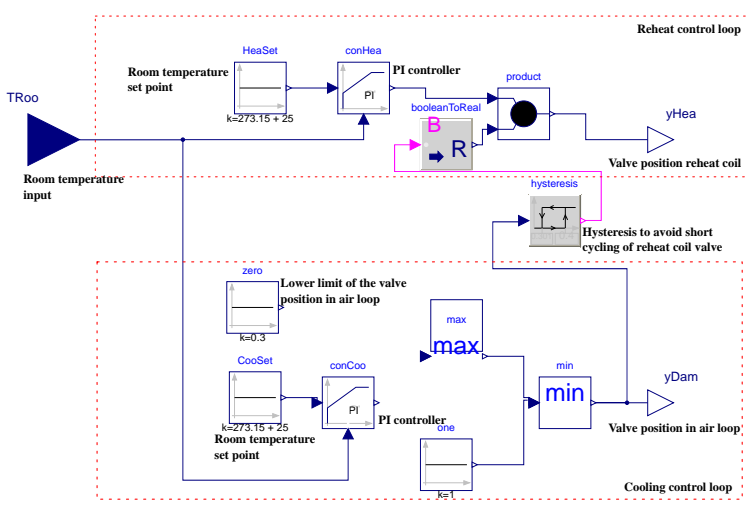

Figure 9. Controller in VAV terminal box
From Figure 10 to Figure 12, the dynamic response of the VAV terminal box and indoor environment is shown. In the beginning, as shown in Figure 10, the room temperature is initially higher than the set point $\left(25^{\circ} \mathrm{C}\right)$, the opening ratio of the valve in the cold air loop is decreasing from 1.0 to 0.3 as shown in Figure 11. The mass flow rate of the supply air as shown in Figure 12 then drops from $0.120 \mathrm{~kg} / \mathrm{s}$ to $0.044 \mathrm{~kg} / \mathrm{s}$. Since the reheat coil does not turn on, the supply air temperature remains constant as $16{ }^{\circ} \mathrm{C}$, as shown in Figure 13 .

At around 60 seconds, when the opening ratio of the valve in the cold air loop reaches $30 \%$, and the room temperature is lower than the set point (Figure 10), the reheat coil is turned on. Then, the room temperature is increased and meets the set point at around 160 seconds. Since the room temperature is lower than the set point at this period (60-160 seconds), the opening ratio of the valve in cold air loop remains a minimum of $30 \%$ and the opening of the valve in reheat coil first climbs up and then drops, as shown in Figure 11. As a result, the mass flow rate of the supply air remains constant at $0.044 \mathrm{~kg} / \mathrm{s}$ (Figure 12). Consequently, one can see in Figure 13 that the supply air temperature first increases to a maximum of $25.4^{\circ} \mathrm{C}$ and then gradually drops to $23.0^{\circ} \mathrm{C}$, along with the change of opening of the valve in reheat coil.

From 160 to 225 seconds, the room temperature is higher than the set point and their difference is decreasing (Figure 10). As the difference changes, the opening of the valve in the cold air loop increases from 0.3 to $0.4 \mathrm{~kg} / \mathrm{s}$. Though the room temperature is higher than set point, due to the hysteresis embedded in the controller, the reheat coil is still on with a small opening (Figure 11). Thus, the supply air temperature is higher than $16{ }^{\circ} \mathrm{C}$ and generally decreasing with the valve opening becoming smaller (Figure 13).

After approximately 225 seconds, the room temperature is approaching the set point (Figure 10). At end of the simulation ( $15 \mathrm{~min})$, the difference between room temperature and the set point is marginal. Since the room temperature is higher than set point and the opening of the valve in cold air loop is larger than 0.4, the reheat coil is turned off (Figure 11) and supply air temperature is $16^{\circ} \mathrm{C}$ (Figure 13).

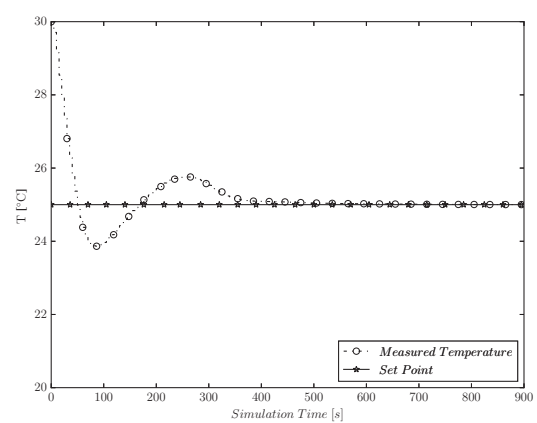


Figure 10. Zone 1 temperature control

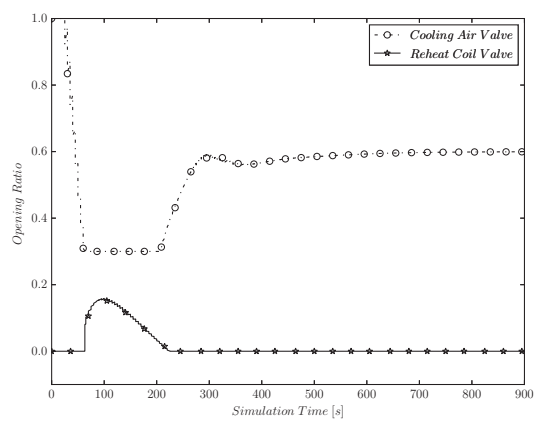

Figure 11. Control outputs from VAV terminal box

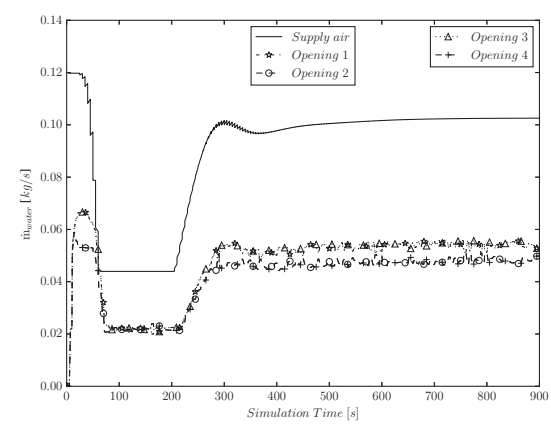

Figure 12. Mass flow rates at different openings

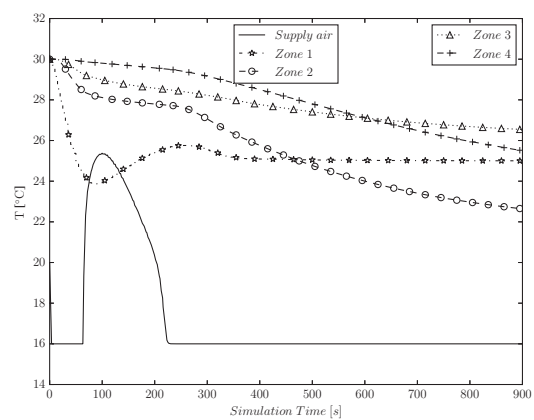

Figure 13. Zone temperature in the space

Note that we presented the mass flow rate of supply air and at different openings in the space in Figure 12. We can clearly identify the mass flow rate difference at Opening 1 and Opening 2, which would be ignored if a multizone model is used. Due to the mass conservation law, the mass flow rate at Opening 1 and Opening 3 are equal, and the same rule applies to Opening 2 and Opening 4.

Figure 13 shows the temperature of supply air and other zones. As the room temperature in Zone 1 approaches set point of $25{ }^{\circ} \mathrm{C}$, the temperature at Zone 3 and Zone 4 gets close to the set point with an error of
$1.0{ }^{\circ} \mathrm{C}$. However, in the Zone 2, the temperature is 21.7 ${ }^{\circ} \mathrm{C}$, which is as expected, because part of the cold supply air in Zone 1 is directly injected into Zone 2 as opening 1 is facing to the inlet of Zone 2 .

\section{Conclusion and Discussion}

The results shown in the validation case prove that the coupled simulation is capable of handling the airflow simulation in a multi-zone space with non-uniform momentum distribution. By further adding a VAV terminal box to the validation case, the coupled simulation model further demonstrates its application potential in indoor climate control and its capability to capture the dynamics of the building system as well as the indoor environment. In the future, more case studies need to be performed to holistically assess the coupled simulation model such as contaminant control and fire or smoke control. Moreover, the FFD simulation can be performed in parallel (Tian, Sevilla, and Zuo 2017) or a reduced order model such as in situ adaptive tabulation ( $\mathrm{Li}$ et al. 2016; Tian, Sevilla, Li, et al. 2017) can be further used to accelerate the computation speed.

\section{Acknowledgements}

This research was supported by the National Science Foundation under Award No. IIS-1633338 and the U.S. Department of Energy under Contract No. DEEE0007688. This research was also supported in part by the U.S. Defense Threat Reduction Agency. LBNL's research was performed under U.S. Department of Energy Contract No. DE-AC02-05CH11231.

\section{References}

Bonvini, M., M. Popovac, and A. Leva. 2014. Sub-Zonal Computational Fluid Dynamics in an ObjectOriented Modelling Framework. Proceedings of the Building Simulation.

Chen, Q. 2009. Ventilation Performance Prediction for Buildings: A Method Overview and Recent Applications. Building and Environment, 44 (4):848-58.

Chen, Q., and W. Xu. 1998. A Zero-Equation Turbulence Model for Indoor Airflow Simulation. Energy and Buildings, 28 (2):137-44.

Chorin, A. J. 1967. A Numerical Method for Solving Incompressible Viscous Flow Problems. Journal of Computational Physics, 2 (1):12-26.

Courant, R., E. Isaacson, and M. Rees. 1952. On the Solution of Nonlinear Hyperbolic Differential Equations by Finite Differences. Communications on Pure and Applied Mathematics, 5 (3):243-55.

Crawley, D. B., L. K. Lawrie, F. C. Winkelmann, W. F. Buhl, Y. J. Huang, C. O. Pedersen, R. K. Strand, et al. 2001. Energyplus: Creating a New-Generation Building Energy Simulation Program. Energy and Buildings, 33 (4):319-31. 
Department of Energy. 2011. "Building Energy Data Book." In.

Dols, W. S., and G. N. Walton. 2002. Contamw 2.0 User Manual: Multizone Airflow and Contaminant Transport Analysis Software: US Department of Commerce, Technology Administration, National Institute of Standards and Technology.

Fisk, W. J. 2000. Health and Productivity Gains from Better Indoor Environments and Their Relationship with Building Energy Efficiency. Annual Review of Energy and the Environment, 25:537-66.

Fritzson, P. 1998. Modelica - a Language for Equation-Based Physical Modeling and High Performance Simulation. Applied Parallel Computing, 1541:14960.

Jin, M., W. Zuo, and Q. Chen. 2012. Improvements of Fast Fluid Dynamics for Simulating Air Flow in Buildings. Numerical Heat Transfer, Part B: Fundamentals, 62 (6):419-38.

Kats, G. 2003. Green Building Costs and Financial Benefits: Massachusetts Technology Collaborative Boston, MA.

Klein, S. A., J. A. Duffie, and W. A. Beckman. 1976. Trnsysa Transient Simulation Program. Ashrae Transactions, 82:623.

Kropf, S., and G. Zweifel. 2001. Validation of the Building Simulation Program Ida-Ice According to Cen 13791 "Thermal Performance of BuildingsCalculation of Internal Temperatures of a Room in Summer without Mechanical Cooling-General Criteria and Validation Procedures". Hochschule Technik+ Architektur Luzern. HLK Engineering.

Li, D., W. Tian, Z. Wetter, Wangda, and Michael. 2016. Simulation Using in Situ Adaptive Tabulation and Fast Fluid Dynamics. IBPSA-USA Journal, 6 (1).

Liu, G., J. Zhang, and A. Dasu. 2012. Review of Literature on Terminal Box Control, Occupancy Sensing Technology and Multi-Zone Demand Control Ventilation (Dcv). US Department of Energy, Tech. Rep.

Norrefeldt, V., G. Grün, and K. Sedlbauer. 2012. VepzoVelocity Propagating Zonal Model for the Estimation of the Airflow Pattern and Temperature Distribution in a Confined Space. Building and Environment, 48:183-94.

Strachan, P., G. Kokogiannakis, and I. Macdonald. 2008. History and Development of Validation with the Esp-R Simulation Program. Building and Environment, 43 (4):601-9.

Tian, W., A. T. Sevilla, D. Li, W. Zuo, and M. Wetter. 2017. Fast and Self-Learning Indoor Airflow Simulation Based on in Situ Adaptive Tabulation. Journal of Building Performance Simulation.

Tian, W., T. A. Sevilla, and W. Zuo. 2017. A Systematic Evaluation of Accelerating Indoor Airflow Simulations Using Cross-Platform Parallel Computing. Journal of Building Performance $\begin{array}{lll}\text { Simulation, } 10 & \text { (3):243-55. }\end{array}$ 10.1080/19401493.2016.1212933.

Tian, W., and W. Zuo. 2013. Literature Review and Research Needs to Couple Building Energy and Airflow
Simulation. Proceedings of the Proceedings of the the APEC Conference on Low-carbon Towns and Physical Energy Storage.

Wang, L. 2007. Coupling of Multizone and CFD Programs for Building Airflow and Contaminant Transport Simulations: ProQuest.

Wang, L., and Q. Chen. 2005. On Solution Characteristics of Coupling of Multizone and CFD Programs in Building Air Distribution Simulation. Proceedings of the Proceedings of the 9 th International IBPSA Conference (Building Simulation 2005), Montreal, Canada.

Wang, L., and Q. Chen. 2007. Validation of a Coupled Multizone-CFD Program for Building Airflow and Contaminant Transport Simulations. HVAC\&R Research, 13 (2):267-81.

Wang, L. L., and Q. Chen. 2008. Evaluation of Some Assumptions Used in Multizone Airflow Network Models. Building and Environment, 43 (10):1671-7.

Wang, M., and Q. Chen. 2009. Assessment of Various Turbulence Models for Transitional Flows in an Enclosed Environment (Rp-1271). HVAC\&R Research, 15 (6):1099-119.

Wetter, M. 2006a. Multizone Airflow Model in Modelica. Proc. of the 5-th International Modelica Conference, 2:431-40.

Wetter, M. 2006b. Multizone Airflow Model in Modelica. Proceedings of the Proc. of the 5-th International Modelica Conference.

Wetter, M. 2009. Modelica-Based Modeling and Simulation to Support Research and Development in Building Energy and Control Systems. Journal of Building Performance Simulation, 2 (2):143-61.

Wetter, M., W. Zuo, T. S. Nouidui, and X. Pang. 2014. Modelica Buildings Library. Journal of Building Performance Simulation, 7 (4):253-70. doi: 10.1080/19401493.2013.765506.

Yang, P. 2013. "Real-Time Building Airflow Simulation Aided by GPU and FFD." Concordia University.

Zhai, Z., Q. Chen, P. Haves, and J. H. Klems. 2002. On Approaches to Couple Energy Simulation and Computational Fluid Dynamics Programs. Building and Environment, 37 (8):857-64.

Zuo, W., and Q. Chen. 2009. Real-Time or Faster-Than-RealTime Simulation of Airflow in Buildings. Indoor Air, 19 (1):33-44.

Zuo, W., and Q. Chen. 2010. Fast and Informative Flow Simulations in a Building by Using Fast Fluid Dynamics Model on Graphics Processing Unit. Building and Environment, 45 (3):747-57.

Zuo, W., M. Wetter, D. Li, M. Jin, W. Tian, and Q. Chen. 2014. Coupled Simulation of Indoor Environment, HVAC and Control System by Using Fast Fluid Dynamics and Modelica. Proceedings of the 2014 ASHRAE/IBPSA-USA Building Simulation Conference, Atlanta, GA, Sep. 10-12.

Zuo, W., M. Wetter, W. Tian, D. Li, M. Jin, and Q. Chen. 2016. Coupling Indoor Airflow, HVAC, Control and Building Envelope Heat Transfer in the Modelica Buildings Library. Journal of Building Performance Simulation, 9 (4):366-81. 